\title{
Body weight regulation and gonadal hormone manipulations in female Eastern chipmunks
}

\author{
KATHERINE BRUCE and DANIEL ESTEP \\ University of Georgia, Athens, Georgia
}

\begin{abstract}
Vulval size, body weight, food intake, and food hoarding of 20 female Eastern chipmunks born in the wild were monitored for 3 weeks following ovariectomy or sham operation and subsequent estradiol benzoate (EB) or oil-vehicle replacement therapy. EB treatment induced vulval swelling; however, neither ovariectomy nor EB affected body weight, food intake, or food hoarding. The relationship between gonadal hormones and body weight regulation in chipmunks appears to be more complex than is assumed by current theory.
\end{abstract}

Gonadal hormones can affect body weight, food intake, and food hoarding in several species (Beatty, 1979; Bermant \& Davidson, 1974; Leshner, 1978). A theory of a lipostatic set point about which body weight is regulated has been postulated (Beatty, 1979; Roy \& Wade, 1977; Wade, 1972) to explain the interrelationships among these variables. When weight falls below or rises above this set point, an animal engages in behavior which restores the weight. For rodents, it has been suggested that both daily food intake (short-term regulation) and hoarding (longer-term regulation) are activated when body weight falls below the set point and are depressed when body weight rises above the set point (Nyby \& Thiessen, 1980).

The research to date has focused primarily on laboratory species. Cycling rats and hamsters show an inverse relationship among the circulating levels of endogenous estrogen and body weight, food intake, and food hoarding (Estep, Lanier, \& Dewsbury, 1978; Herberg, Pye, \& Blundell, 1972; Morin \& Fleming, 1978; Wade, 1972). Ovariectomy may result in hyperphagia, weight gain, and/or increased food hoarding for both rats (Coling \& Herberg, 1982; Pye \& Herberg, 1972; Roy \& Wade, 1977) and hamsters (Morin \& Fleming, 1978). These effects can be reversed by estrogen therapy. Such therapy produces transient hypophagia and weight loss in both rats and hamsters, and, additionally, depressed food hoarding in rats (Coling \& Herberg, 1982; Morin \& Fleming, 1978; Pye \& Herberg, 1972; Roy \& Wade, 1977; Wade, 1972, 1975).

Nyby (1974; Nyby \& Thiessen, 1980) proposed a hypothetical environmental mechanism to explain how seasonally induced body weight fluctuations and hormone levels may be related in seasonally breeding wild animals:

This study was completed in partial fulfillment of the requirements for the MS degree at the University of Georgia by the first author. We thank Brad N. Bunnell and Lelon J. Peacock for critical review of the thesis and Martha Jo Clemmons and Lydia Woodard for typing the manuscript. Address correspondence to Katherine Bruce, Department of Psychology, University of North Carolina at Wilmington, Wilmington, NC 28403-3297.
Either this mechanism causes a change in both hormone secretion and weight regulation or a change in hormone secretion, which in turn affects body weight. To investigate this hypothesis, we used Eastern chimpmunks (Tamias striatus), which are both seasonal breeders and hoarders.

Eastern chipmunks have one or two breeding seasons a year, in early spring and/or midsummer (Yahner, 1978). They hoard large amounts of food in the wild (Elliott, 1978; Yahner, 1978). Females show seasonal fluctuations in body weight; increases in weight are observed under laboratory conditions from late summer into winter (Wrazen \& Wrazen, 1982). Thus, a circannual rhythm may be associated with gonadal hormone levels and longterm weight regulation. Therefore, we examined the effects of gonadal hormone manipulations on body weight, food intake, food hoarding, and, in addition, vulval area, a physiological change associated with estrus.

\section{METHOD}

\section{Subjects}

Twenty female Eastern chipmunks of unknown ages had been trapped within the city limits of Athens, Georgia, and housed in the laboratory for periods ranging from 10 months to 4.5 years. The animals were maintained in a temperature-controlled environment on a natural light-dark cycle. Food and water were freely available.

\section{Apparatus}

The subjects lived in individual terraria, measuring $62 \times 32 \times 29 \mathrm{~cm}$, with hardware cloth tops. A 1,892-ml mason jar painted black served as a nesting area, with paper towels as nesting material. Sanicel bedding material covered the floors of the terraria. Plastic containers $(600 \mathrm{ml})$ suspended from the side of each terrarium were filled with fresh Purina Laboratory Chow daily.

\section{Procedure}

The animals were tested from April to July of 1980 during their normal breeding seasons. At $1700 \mathrm{~h}$ each day, body weight, food intake, and food hoarding (larder and scatter hoarding) were measured. Vulval size (mm length $\times$ mm width) was measured daily to detect any changes in estrous swelling, as vulval enlargement is characteristic of females in estrus (Smith \& Smith, 1975).

After 7 days of baseline measurements were taken, half the chipmunks were ovariectomized by bilateral flank incisions (ovx group, $n=9$; 
1 subject died after surgery). In the other group (sham group, $n=10$ ), each ovary was exposed and touched. Body weight, food intake, food hoarding, and vulval size were recorded for 21 days.

Members of the sham group were then ovariectomized and monitored for an additional 21 days. Twenty-one days after their respective ovariectomies, half of the subjects in both groups were given subcutaneous daily injections of $2 \mu \mathrm{g}$ estradiol benzoate (EB) in $.05 \mathrm{ml}$ sesame oil (EB group, $n=9$ ) for 21 days and half were injected with oil alone for 21 days (oil group, $n=9 ; 1$ subject died during treatment). This dosage of EB falls within the range used for other small rodents in body weight regulation studies (Coling \& Herberg, 1982; Landau \& Zucker, 1976; Maass \& Wade, 1977; Morin \& Fleming, 1978; Roy \& Wade, 1977). Body weight, food intake, food hoarding, and genital size were recorded daily for the 3-week injection period and for 7 days postinjection.

\section{RESULTS AND DISCUSSION}

Table 1 presents the means and standard errors for the ovx and sham groups for each dependent measure during the 3 weeks after initial surgery. Ovariectomy, compared to sham operation, produced no significant changes in body weight, food intake, food hoarding, or vulval size $(p>.05)$. However, for both groups, body weight and food intake increased significantly over the 3 weeks after surgery $[F(2,28)=15.51$ and $F(2,28)=12.74$, $p<.001$, for body weight and food intake, respectively]. Post hoc Newman-Keuls tests revealed that both measures were lower during the first week after surgery than during the second and third weeks after surgery $(p<.05)$. This suggests that the subjects' body weight and food intake were affected by postsurgical trauma.

The lack of effect of ovariectomy was unexpected and may have been due to the fact that the subjects were "functionally ovariectomized" prior to surgery. Even though this study was conducted during the breeding seasons, the subjects' ovaries appeared to be small and their vulvae were not enlarged. If the ovaries were inactive, ovariectomy would not be expected to have an effect.

As seen in Table 2, EB treatment, compared to oil alone, had no effect on body weight, food intake, or food hoarding during the 3-week injection period $(p>.05)$. For both groups, body weight and food intake increased over the 3-week injection period $[F(2,28)=18.91$, $p<.001$ and $F(2,28)=15.98, p<.001$, for body weight and food intake, respectively]. This suggests that the subjects may have experienced trauma from the onset

Table 1

Mean Weekly Scores for Ovariectomized (Ovx) and Sham Operated (Sham) Animals

\begin{tabular}{llrrr}
\hline & & Week 1 & \multicolumn{1}{c}{ Week 2 } & \multicolumn{1}{c}{ Week 3 } \\
\hline Body Weight (g) & Ovx & $117.5(2.9)$ & $119.7(3.1)$ & $120.4(2.7)$ \\
& Sham & $119.6(5.3)$ & $126.0(5.2)$ & $126.7(5.7)$ \\
Food Intake (g) & Ovx & $10.2(0.9)$ & $11.9(1.1)$ & $11.9(1.0)$ \\
& Sham & $10.4(0.6)$ & $11.7(0.5)$ & $11.5(0.7)$ \\
Food Hoarded (g) & Ovx & $14.8(5.2)$ & $11.6(3.6)$ & $8.8(3.6)$ \\
& Sham & $12.5(4.3)$ & $13.4(4.8)$ & $16.7(5.3)$ \\
Vulval Area (mm) & Ovx & $16.8(0.5)$ & $17.0(0.4)$ & $16.2(0.6)$ \\
& Sham & $15.4(1.0)$ & $17.0(0.9)$ & $17.1(0.9)$ \\
\hline
\end{tabular}

Note-Standard errors are presented in parentheses.
Table 2

Mean Weekly Scores for Animals Injected with Estradiol Benzoate (EB) or Oil

\begin{tabular}{llrrr}
\hline & & \multicolumn{1}{c}{ Week 1 } & \multicolumn{1}{c}{ Week 2 } & \multicolumn{1}{c}{ Week 3 } \\
\hline Body Weight* (g) & EB & $119.3(3.1)$ & $121.5(3.1)$ & $125.4(3.1)$ \\
& Oil & $127.9(4.5)$ & $130.2(4.9)$ & $131.6(4.9)$ \\
Food Intake (g) & EB & $10.2(1.3)$ & $12.2(0.9)$ & $12.9(0.6)$ \\
& Oil & $11.3(0.7)$ & $12.6(1.0)$ & $12.4(1.2)$ \\
Food Hoarded* (g) & EB & $8.6(3.2)$ & $10.9(2.9)$ & $9.5(2.5)$ \\
& Oil & $4.4(2.5)$ & $5.5(4.5)$ & $3.4(1.1)$ \\
Vulval Area (mm) & EB & $33.4(2.2)$ & $44.0(3.2)$ & $45.2(3.8)$ \\
& Oil & $19.3(0.6)$ & $19.0(1.0)$ & $18.7(1.0)$ \\
\hline
\end{tabular}

Note-Standard errors are presented in parentheses. *Preinjection values for these variables were significantly different across groups. Therefore, we conducted analyses of covariance, using the preinjection value as the covariate.

of injections. Vulval area significantly increased for the EB treated female $[F(2,28)=115.56, p<.001]$. Thus, the circulating estradiol levels were sufficient to produce the physiological changes characteristic of estrus, but not to induce the expected changes in body weight, food intake, and food hoarding.

The reasons for the negative findings of this study are not clear. It is possible that factors such as the choice of hormone dosage, age of the animals, housing and testing conditions, season of testing, or individual differences were involved. However, the levels of these factors (especially hormone dosage) in the present study were chosen to be similar to those used in studies that have reported positive findings for other rodent species. These specific factors should be investigated more precisely in future studies, since not all rodent species respond in the same ways (see Wade, 1976).

Even though support for Nyby's (1974; Nyby \& Thiessen, 1980) hypothesis was not obtained, the present findings are critical since this study was designed to investigate several factors vital to the validity of Nyby's hypothesis. First, wild-born, rather than laboratory-born, animals were tested. Second, the subjects were maintained under natural photoperiod conditions, rather than conditions of constant lighting. Third, food hoarding, which represents an often neglected component of body weight regulation, was monitored. These factors should be examined more closely in body weight regulation studies.

It is clear that the environmental mechanism underlying circannual body weight regulation and gonadal hormone secretion is not as simple as that proposed by Nyby (1974; Nyby \& Thiessen, 1980). The generalizability of the proposed inverse relationship between gonadal hormones and body weight regulation has been challenged by data obtained for at least three other species. Negative results similar to those found in the present study have also been reported for gerbils (Maass \& Wade, 1977) and for hamsters (Zucker, Wade, \& Ziegler, 1972). Furthermore, the relationship between gonadal hormones and food hoarding by hamsters found by Estep et al. (1978) has not been reliably replicated in our laboratory (Estep, Bruce, \& Forand, 1978-1981). In addition, in golden man- 
tled ground squirrels, gonadal hormone levels were not found to affect circannual body weight regulation (Zucker \& Boshes, 1982).

In a recent review, Crews (1984) concluded that there may be no causal relationships among gamete production, gonadal hormone production, and mating in seasonally reproducing vertebrates. It seems reasonable to suggest that gonadal hormones and body weight regulation may also be dissociated. It is difficult to confirm that causal relationships do not exist among variables, and the present data certainly provide no such confirmation. However, investigators should be aware of two possibilities: (1) the relationship between gonadal hormones and body weight regulation may be more complex than previously suspected, and (2) in some species, the variables may be unrelated.

\section{REFERENCES}

Beatty, W. W. (1979). Gonadal hormones and sex differences in nonreproductive behaviors in rodents: Organizational and activational influences. Hormones \& Behavior, 12, 112-163.

Bermant, G., \& Davidson, J. (1974). Biological bases of sexual behavior. New York: Harper \& Row.

Coling, J. G., \& Herberg, L. J. (1982). Effect of ovarian and exogenous hormones on defended body weight, actual body weight, and the paradoxical hoarding of food by female rats. Physiology \& Behavior, 29, 687-691.

CREws, D. (1984). Gamete production, sex hormone secretion, and mating behavior uncoupled. Hormones \& Behavior, 18, 22-28.

ElLotT, L. (1978). Social behavior and foraging ecology of the eastern chipmunk (Tamias striatus) in the Adirondack Mountains. Smithsonian Contributions in Zoology, 265, 107 pp.

EsteP, D. Q., BRUCE, K., \& ForAND, D. (1978-81). [Food hoarding by hamsters under a variety of environmental and hormonal conditions.] Unpublished raw data.

ESTEP, D. Q., LANIER, D. L., \& DewSBURY, D. A. (1978). Variation of food hoarding with the estrous cycle of Syrian golden hamsters (Mesocrietus auratus). Hormones \& Behavior, 11, 259-263.

Herberg, L. J., Pye, J. G., \& Blundell, J. E. (1972). Sex differences in the hypothalamic regulation of food hoarding: Hormones versus calories. Animal Behaviour, 20, 186-191.

LANDAU, I. T., \& ZUCKER, I. (1976). Estrogenic regulation of body weight in the female rat. Hormones \& Behavior, 7, 29-39.
LeShNER, A. I. (1978). An introduction to behavioral endocrinology. New York: Oxford University Press.

MAass, C. A., \& WADE, G. N. (1977). Effects of gonadal hormones on eating and body weight in Mongolian gerbils (Meriones unguiculatus). Hormones \& Behavior, 9, 178-187.

Morin, L. P., \& FlEming, A. S. (1978). Variation of food intake and body weight with estrous cycle, ovariectomy, and estradiol benzoate treatment in hamsters (Mesocrietus auratus). Journal of Comparative \& Physiological Psychology, 92, 1-6.

NyBY, J. (1974). Physiological regulation of food hoarding in the Mongolian gerbil (Meriones unguiculatus). Unpublished doctoral dissertation, University of Texas at Austin.

NYBY, J., \& THIESSEN, D. D. (1980). Food hoarding in the Mongolian gerbil (Meriones unguiculatus): Effects of food deprivation. Behavioral \& Neural Biology, 30, 39-48.

PYE, J. G., \& Herberg, L. J. (1972). Sexual dimorphism in the hypothalamic organization of hoarding behavior. Hormones, 3, 282-293.

RoY, E. J., \& WADE, G. N. (1977). Role of food intake in estradiol induced body weight changes in female rats. Hormones \& Behavior, 8, 265-274.

SMITH, D. A., \& SMrTh, L. C. (1975). Oestrus, copulation, and related aspects of reproduction in female eastern chipmunks, Tamias striatus (Rodentia: Sciuridae). Canadian Journal of Zoology, 53, 756-767.

WADE, G. N. (1972). Gonadal hormones and behavioral regulation of body weight. Physiology \& Behavior, 8, 523-534.

WADE, G. N. (1975). Some effects of ovarian hormones on food intake and body weight in female rats. Journal of Comparative \& Physiological Psychology, 88, 183-193.

WADE, G. N. (1976). Sex hormones, regulatory behaviors and body weight. In J. S. Rosenblatt, R. A. Hinde, E. Shaw, \& C. G. Beer (Eds.), Advances in the study of behavior (Vol. 6). New York: Academic Press.

Wrazen, J. A., \& Wrazen, L. A. (1982). Hoarding, body mass dynamics and torpor as components of the survival strategy of the eastern chipmunk (Tamias striatus). Journal of Mammalogy, 63, 63-72.

YAHNER, R. H. (1978). Adaptive nature of the social system and behavior in the eastern chipmunk, Tamias striatus. Behavioral Ecology \& Sociobiology, 3, 397-427.

ZUCKER, I., \& Boshes, M. (1982). Circannual body weight rhythms of ground squirrels: Role of gonadal hormones. American Journal of Physiology, 243, R546-551.

ZUCKER, I., WADE, G. N., \& ZIEGLER, R. (1972). Sexual and hormonal influences on eating, taste preferences, and body weight of hamsters. Physiology \& Behavior, 8, 101-111.

(Manuscript received for publication August 11, 1986.) 